\title{
Changes in phenolic acid abundance involved in low temperature and Microdochium nivale (Samuels and Hallett) cross-tolerance in winter triticale ( $x$ Triticosecale Wittmack)
}

\author{
Gabriela Gołębiowska-Pikania ${ }^{1}$ - Michał Dziurka ${ }^{2} \cdot$ Iwona Wąsek $^{1} \cdot$ Katarzyna Wajdzik $^{1} \cdot$ Mateusz Dyda $^{1}$. \\ Maria Wędzony'
}

Received: 20 July 2018 / Revised: 5 February 2019 / Accepted: 8 February 2019 / Published online: 22 February 2019

(c) The Author(s) 2019

\begin{abstract}
Tolerance to the pink snow mould resulting from Microdochium nivale infection is an essential trait of triticale ( $x$ Triticosecale) for winter survival. In the present study, we aimed to verify whether the presence and concentration of free and cell wall-bound phenolic acids are important factors in triticale responses to M. nivale infection. Based on 3 years' testing of triticale tolerance, 2 out of 92 doubled haploid triticale lines derived from 'Hewo' $\times$ 'Magnat' $F_{1}$ hybrid were selected, which are the most tolerant and the most sensitive to $M$. nivale infection. Plants were grown along with their parents under controlled conditions, pre-hardened and cold-hardened, while non-hardened plants served as the control. Hardened plants were covered with the artificial snow-imitating covers and inoculated with M. nivale mycelium, while the control plants were treated the same way except the infection. The aim of the study was to identify differences in the initial content and composition of phenolics under the influence of applied stresses. Conducted HPLC analysis showed that the most abundant were ferulic, rosmarinic, chlorogenic, sinapic, and trans-cinnamic acids. The contents of most of phenolics depended on genotype and growth conditions. Two cell wall-bound sinapic and trans-cinnamic acids, could be indicated as potentially related to the increased snow mould tolerance of winter triticale seedlings. A correlation between the total phenolic levels with the tolerance was not found; however, the proportion between the total levels of cell wall-bound and free phenolic compounds under low temperature could play a role prior to M. nivale infection.
\end{abstract}

Keyword Winter triticale $\cdot$ Cold-hardening $\cdot$ Microdochium nivale $\cdot$ Cross-tolerance $\cdot$ Free phenolic acids $\cdot$ Cell wall-bound phenolic acids

\begin{tabular}{|c|c|}
\hline Abbre & tions \\
\hline BA & Benzoic acid \\
\hline $\mathrm{p}-\mathrm{CA}$ & Para-coumaric acid \\
\hline CfA & Caffeic acid \\
\hline
\end{tabular}

Communicated by S. Srivastava.

Electronic supplementary material The online version of this article (https://doi.org/10.1007/s11738-019-2823-z) contains supplementary material, which is available to authorized users.

Gabriela Gołębiowska-Pikania

gabriela.golebiowska-pikania@up.krakow.pl

Institute of Biology, Pedagogical University of Cracow, Podchorążych 2, 30-054 Kraków, Poland

2 The Franciszek Górski Institute of Plant Physiology, Department of Developmental Biology, Polish Academy of Sciences, Niezapominajek 21, 30-239 Kraków, Poland

$\begin{array}{ll}\text { ChA } & \text { Chlorogenic acid } \\ \text { CiA } & \text { Trans-cinnamic acid } \\ \text { DH } & \text { Line doubled haploid line } \\ \text { 3,4-Dhb } & \text { 3,4-Dihydroxobenzoic acid } \\ \text { DW } & \text { Dry weight } \\ \text { FA } & \text { Ferulic acid } \\ \text { FPhA } & \text { Free phenolic acids } \\ \text { FW } & \text { Fresh weight } \\ \text { GA } & \text { Gallic acid } \\ \text { GeA } & \text { Gentisic acid } \\ \text { p-Hb } & \text { P-hydroxobenzoic acid } \\ \text { HvA } & \text { Homovanillic acid } \\ \text { P } & \text { The whole plant infection index calculated } \\ & \text { according to Townsend and Heuberg's equation } \\ \text { P }^{2012 / 13} & \text { The whole plant infection index from the sea- } \\ & \text { son 2012/13 } \\ \text { P }^{2010-13} & \text { The average whole plant infection index from } \\ & \text { seasons 2010-13 }\end{array}$


PAL Phenylalanine ammonia-lyase

PhA Phenolic acids

RA Rosmarinic acid

ROS Reactive oxygen species

SA Salicylic acid

SiA Sinapic acid

SyA Syringic acid

WBPhA Cell wall-bound phenolic acids

VA Vanillic acid

\section{Introduction}

In plant cells, phenolic acids can be detected as free molecules or as compounds bound to cell walls and/or polymerised. Phenolic acids play a significant role in scavenging the reactive oxygen species (ROS) under different environmental stresses and are involved in the structural and functional changes of the plant cell wall (Nicholson and Hammerschmidt 1992). Moreover, the increase in activity of phenylalanine ammonia-lyase (PAL), the key enzyme of phenols' metabolic pathways, is proposed to be a marker of plant reaction to stress (Hura et al. 2008; Leszczyński 1985; Naz et al. 2014). The free trans-cinnamic acid (CiA) is the primary product of its activity and the precursor of other phenolic acids. It also shows bacteriostatic (Rastogi et al. 1998) and antiviral (Yoon et al. 2007) pharmacological activity. In response to the infection with pathogen, plant polyphenols are used in lignin polymerization that serves cell wall fortification against mechanical damages and fungal hyphae penetration (Lattanzio et al. 2006). Various phenolic acids revealed antifungal activity and they were shown to influence mycotoxins levels. Among them, the most commonly reported are the following: ferulic acid (FA), p-coumaric acid (p-CA), syringic acid (SyA), benzoic acid (BA), and sinapic acid (SiA) (Aristimuño Ficoseco et al. 2014; Assabgui et al. 1993; Bollina et al. 2011; Boutigny et al. 2010; Engelharclt et al. 2002; Lattanzio et al. 2006; McKeehen et al. 1999; Miedes et al. 2014; Nicholson and Hammerschmidt 1992; Prasad et al. 2010; Siranidou et al. 2002; Southerton and Deverall 1990). Another phenolic compound, which is the free salicylic acid (SA), is the one of the most important signalling molecules of defense response against invading pathogens (Lattanzio et al. 2006; Naz et al. 2014; $\mathrm{Ng}$ et al. 2011; Wang et al. 2007). In general, increased antioxidative activity, in which phenolic compounds are involved, neutralizes the overdose of ROS released under the influence of stress factors, helps plants surviving both cold (Scebba et al. 1999; Shigeoka et al. 2002) and pathogen infection (Gołębiowska et al. 2011; Hanifei et al. 2013; Ivanov et al. 2004; Király et al. 2007; Kumar et al. 2009; Płażek et al. 2003).
Tolerance to snow moulds is an essential trait for the winter survival of cereals, and among them triticale ( $x$ Triticosecale Wittm.) (Gołębiowska and Wędzony 2009; Hudec and Bokor 2002; Sliesaravičius et al. 2006; SzechyńskaHebda et al. 2011, 2013; Zhukovsky and Ilyuk 2010). Microdochium nivale (Samuels and Hallett1983) is one of the most frequent and virulent fungi in the temperate and cold climates. Tolerance towards snow moulds is a complex quantitative trait, which is likely dependent on many genes and influenced by environmental factors. Previously used fungicides against snow mould turned out to be very harmful to the environment and not efficient (Bateman 2008; Leroux et al. 2006; Nielsen et al. 2013; Parry et al. 2008; Dyda et al. 2018); therefore, it is essential to find tolerant genotypes and dissect the mechanisms of tolerance to introduce the trait into the wide range of new cultivars.

Our previous studies on the $M$. nivale tolerance of winter triticale showed that induction of defence was induced only in cold-acclimated plants (Dubas et al. 2011; Gołębiowska and Wędzony 2009; Gołębiowska et al. 2011; SzechyńskaHebda et al. 2011, 2013; Żur et al. 2013; Dyda et al. 2018). Seedlings of triticale cultivars, 'Hewo' and 'Magnat', were entirely destructed by $M$. nivale mycelium when inoculation was not preceded by the low temperature hardening (Gołębiowska and Wędzony 2009). When subjected to low temperature, they achieved different levels of tolerance, i.e. seedlings of cv. 'Magnat' continuously were sensitive while the tolerance of cv. 'Hewo' increased gradually during cold exposure (Gołębiowska and Wędzony 2009; Gołębiowska et al. 2011; Szechyńska-Hebda et al. 2011, 2013; Dyda et al. 2018). The laboratory tests were in accordance with field experiments (personal data not published). These observations make the above cultivars a model for studying mechanisms underlying the snow mould tolerance. Furthermore, with use of the anther culture method (Wędzony 2003), we developed a population of $92 \mathrm{DH}$ lines from $\mathrm{F}_{1}$ hybrid between the cultivars, differing in the tolerance to snow mould. The $M$. nivale tolerance tests in controlled conditions let us select from the DH population lines that showed the transgression of tolerance and sensitivity in comparison to the parents; therefore, they are included to our present studies to widen the tolerance variability in the studied material while remaining within the same gene pool.

Similarly to our results, other authors have also documented the cold-mediated induction of the resistance response of cereals against $M$. nivale infection, but individual genotypes differ in the tolerance levels (Gaudet et al. 2011; Miedaner et al. 2011; Nakajima and Abe 2011). Despite the long term studies, which biochemical, physiological or anatomical features could serve as a cogent and simple-measurable marker for the selection of the snow mould tolerant genotypes of winter triticale and other cereals is still uncertain. 
Despite the fact that phenolic acids concentration was postulated to play the important role in the controlling plant response to various stresses, including fungal infection (Southerton and Deverall 1990; Siranidou et al. 2002; Hamzehzarghani 2007; Janda et al. 2007; Pociecha et al. 2008; Bollina et al. 2011; Żur et al. 2011), the concentration of phenolic acids has never been studied in triticale seedlings under various environmental conditions and snow mould infection and there is limited information on individual phenolic acids in other cereals.

Therefore, we aimed to study phenolic acid levels in seedlings to identify differences in the initial content and composition of phenolics as well as their changes under the influence of cold-hardening and then during plant vegetation under snow cover with or without the fungal infection. In this paper, the hypothesis was that the phenolic profiles of those genotypes differ after cold treatment and that some of the changes caused by hardening might have an important significance at following conditions under snow cover and pathogen infection. The goal of our study was to widen our basic knowledge on the composition and levels of phenolic acids present in triticale seedlings and to find out whether there are any relationship between phenolic compounds (free and cell wall-bound) and M. nivale tolerance.

\section{Materials and methods}

\section{Plant material}

Two winter triticale ( $x$ Triticosecale Wittmack, $2 n=6 x=42$ ) inbred lines (over nine generations of inbreeding) were derived from parental cultivars 'Magnat' (Danko Plant Breeders Ltd., Poland) and 'Hewo' (Strzelce Plant Breeding-IHAR Group Ltd., Poland). They were tested together with 2 out of 92 doubled haploid lines (DH) (lines DH1 and DH92) derived by the another culture method according to Wędzony (2003) from $\mathrm{F}_{1}$ hybrid between 'Hewo' × 'Magnat' cultivars, which differed in their cold-induced tolerance to $M$. nivale infection under field and controlled conditions as previously reported (Gołębiowska and Wędzony 2009; Dubas et al. 2011, Golebiowska et al. 2011; Szechyńska et al. 2013). The $92 \mathrm{DH}$ lines were preliminarily tested in controlled conditions for their susceptibility to $M$. nivale, and DH1 and DH92 were selected for the present experiments due to the best and the worst performance in the test. The mapping of the population of $92 \mathrm{DH}$ lines and the parental 'Hewo' and 'Magnat' lines with DArT and SSR markers confirmed their homozygotic condition (Tyrka et al. 2015) that makes this set of material especially suited for further experiments.

\section{Plant culture and $M$. nivale sensitivity tests}

The scheme of the environmental conditions is given in Supplement Table S1. The tolerance test was repeated according to the same protocol within 3 years. Well-formed kernels of the selected genotypes were sterilized with $96 \%$ ethanol for $3 \mathrm{~min}$ and subsequently with $25 \%$ commercial sodium hypochlorite mixture of detergents (Domestos, Unilever Polska) for $15 \mathrm{~min}$. Then kernels were washed in sterile water and grown on a filter paper, soaked with sterile water in plastic Petri dishes at $26{ }^{\circ} \mathrm{C}$ in darkness for 2 days. Healthy, well-formed seedlings were planted in a sterile mixture of soil/turf substrate/sand (2/2/1, v/v/v) in multi-pots. Eighteen plants per genotype were planted six in a row in ten rows of multi-pots in a randomized complete block design with three replicates for control non-inoculated and inoculated seedlings separately. On the 7th day, plants were supplemented once with Hoagland and Arnon's (1938) sterile medium, $0.5 \mathrm{~L}$ per pot and all multi-pots were moved to the pre-hardening conditions. After 14 days of pre-hardening, multi-pots were subsequently moved to the hardening conditions for 28 days. After 49 days, pre-hardening and full hardened seedlings plants were covered with watered lignin and black plastic bags to imitate environmental conditions under a snow cover. Seedlings were grown further in darkness in the cold chamber at $4{ }^{\circ} \mathrm{C}$ for 21 days (Supplement Table S1). The control plants were not inoculated, while the remaining plants were inoculated with the fungal soil-borne mycelium derived from the monosporal isolate of Microdochium nivale (isolate no. 38z/5a/01). Mycelium was spread around each seedling in equal portions of $20 \mathrm{~g}$ before putting on the snow imitating cover (more technical details of plants and mycelium handling were previously described by Gołębiowska and Wędzony (2009)).

\section{The phases of the experiment and sampling}

The scheme of the environmental conditions and sampling is given in Supplement Table S1. Eighteen plants per genotype were planted six in a row in ten rows of multi-pots in a randomized complete block design with three replicates for (1) control non-hardened, (2) cold-hardened, (3) control noninoculated, and (4) inoculated seedlings, separately. Samples for biochemical analysis were collected after 49 days from pre-hardened and hardened seedlings (cold-hardened plants). The six control non-hardened seedlings per genotype were grown in the optimal photoperiods of light and temperature for 21 days and then harvested. Then samples were collected from inoculated and non-inoculated plants covered with the artificial snow-imitating cover after 21 days of culture in darkness in the cold chamber at $4{ }^{\circ} \mathrm{C}$ (Supplement Table S1).

For biochemical analyses, all the above-ground parts of six control seedlings from each genotype and six seedlings 
of the treated plants (two different plants per one row from three rows in three different multi-pots) were collected. They were immediately frozen in liquid nitrogen and stored at $-80{ }^{\circ} \mathrm{C}$. Each seedling was considered as one biological replicate.

\section{The HPLC analysis of composition and quantity of phenolic acids}

For chromatographic analyses, frozen samples were lyophilized and then pulverised in mixing mill (MM 400, Retach, Kroll, Germany). Portions of $20 \mathrm{mg}$ of each sample were put into $2 \mathrm{ml}$ Eppendorf Tubes to the $1 \mathrm{ml}$ extraction solution composed of $10 \%$ formic acid in methanol and were placed on a rotary shaker $(250 \mathrm{rpm})$ for $1 \mathrm{~h}$. Then samples were centrifuged $\left(15 \mathrm{~min}, 2200 \times \mathrm{g}, 10^{\circ} \mathrm{C}\right)$ and the supernatant was collected. The extraction was repeated once again, and the methanolic fractions pooled as the free phenolic acids samples. The pellet was hydrolyzed with $3 \mathrm{M} \mathrm{NaOH}$ forming a suspension. Then the suspension was neutralized with concentrated hydrochloric acid. The pellet samples were subjected to the extraction as described above, and methanol fractions were again pooled as the cell wall bound phenolic acids samples. The free and the cell wall bound samples were further processed separately.

Both methanolic extracts were diluted $1 / 3 \mathrm{v} / \mathrm{v}$ with deionised water and cleaned-up on Discovery DPA-6S SPE cartridges ( $3 \mathrm{ml}, 250 \mathrm{mg}$, Sigma). SPE cartridges were activated with $3 \mathrm{ml}$ of water diluted by $10 \%$ formic acid/ methanolic solution $(1 / 3, \mathrm{v} / \mathrm{v})$, then samples were slowly aspirated and cartridges were dried under vacuum for $3 \mathrm{~min}$. Phenolics were washed out from cartridges with $2 \mathrm{ml}$ of the solution of $0.35 \mathrm{M}$ ammonia in $60 \%$ methanol in water. Then samples were evaporated to dryness under nitrogen, reconstituted in $350 \mu \mathrm{l}$ of methanol and after filtration $(0.22 \mu \mathrm{m}$ nylon membrane) injected on to HPLC column. An Agilent Infinity 1260 system equipped with a binary pump, an auto-sampler, and a fluorescence detector (FLD) was used. Phenolic acids were separated on a Zorbax Eclipse Plus Phenyl-Hexyl $3.5 \mu \mathrm{m} 3.0 \mathrm{~mm} \times 100 \mathrm{~mm}$ column under a linear gradient of $2 \%$ formic acid aqueous solution vs. methanol, beginning from $100 \%$ and ending at a $35 \%$ formic acid solution in $14 \mathrm{~min}$, at flow rate of $0.8 \mathrm{ml} / \mathrm{min}$. Two sets of excitation (Ex) and emission (Em) wavelengths were used $(275 \mathrm{~nm}+360 \mathrm{~nm}$ and $275 \mathrm{~nm}+440 \mathrm{~nm})$, which were simultaneously and dynamically changed in time as shown on Supplement Figure S1 A. Excitation and emission maxima were chosen based on the absorption and emission spectra of pure phenolic acid standards acquired in chromatographic separation conditions. The presence of the following 16 phenolic acids were measured: benzoic (BA), para-coumaric (p-CA), caffeic (CfA), chlorogenic (ChA), trans-cinnamic (CiA), 3,4-dihydroxobenzoic (3,4-Dhb), ferulic (FA), gallic
(GA), gentisic (GeA), p-hydroxobenzoic (p-Hb), homovanillic (HvA), rosmarinic (RA), salicylic (SA), sinapic (SiA), syringic (SyA), and vanillic (VA) (Supplement Figure S1).

\section{Statistics}

Statistical analysis of the results was made with the use of Statistica version 13.0 software (StatSoft, Inc., USA). The impact of the variable/ variables was tested by multifactor analysis of variance (ANOVA). The $r$-Pearson test correlation coefficients $(R)$ were calculated between individual phenolic acids contents with both the whole plant infection $\mathrm{P}^{2012-13}$ index from the single season 2012/2013 in which samples for phenolics analysis were collected as well as for the average whole plant infection $\left(\mathrm{P}^{2010-13}\right)$ index from seasons 2010 to 2013. Then $p$-Pearson test correlation coefficients were recalculated for the level of plant tolerance as inverse to those with the level of infection index.

\section{Results}

\section{The rate of seedlings growth in the experimental conditions}

On the 7th day of the experiment, regardless of genotype, seedlings grown in the optimal conditions had one leaf growing through coleoptiles, which corresponds to the Z10 growth stage in the Zadoks' scale (Zadoks 1974, Supplement Table S1). The control seedlings grown constantly for the next 14 days in the optimal conditions developed into seven leaves and two tillers, which corresponds to the Z22 growth stage. After pre-hardening, plants had two unfolded leaves on the main shoot and the third leaf was already visible (Z13 growth stage). After 49 days of growth, cold-hardened plants reached the same developmental stage considering the number of leaves and tillers as the control non-hardened plants after growing in optimal conditions for 21 days, which is the Z22 growth stage (Supplement Table S1). Under the imitation of snow cover, regardless of inoculation, seedlings did not perceptibly proceed further into the next growth stage.

\section{Tolerance/sensitivity of the selected triticale lines to the $M$. nivale infection}

The inoculation experiment (Supplement Table S1) allowed establishing the tolerance level of the $92 \mathrm{DH}$ lines of the mapping population. The three seasons (2010-2013) values of the whole plant infection index $(P)$ for selected genotypes are presented in Table 1 (lower the value of $P$ index, more tolerant are the plants to the infection). Seedlings of the DH1 line showed the highest cold-induced snow mould tolerance, while DH92 plants showed the lowest one. Inbred lines of 
Table 1 The whole plant infection index $(P)$ of two parental winter cultivars 'Hewo' and 'Magnat' and their two progeny DH lines: DH1 (the most tolerant in long term experiments) and DH92 (the most sensitive), inoculated with Microdochium nivale mycelium

\begin{tabular}{lllll}
\hline$P$ index value \pm standard deviation & & \\
\hline Genotype & Season 2010/11 & Season 2011/12 & Season 2012/13 & Average of seasons \\
& & & $2010-2013$ \\
\hline DH1 & $38 \pm 08$ & $48 \pm 02$ & $29 \pm 06$ & $38 \pm 10$ \\
Hewo & $58 \pm 08$ & $33 \pm 03$ & $55 \pm 13$ & $49 \pm 14$ \\
Magnat & $68 \pm 07$ & $47 \pm 05$ & $63 \pm 11$ & $59 \pm 11$ \\
DH92 & $80 \pm 06$ & $51 \pm 14$ & $82 \pm 08$ & $71 \pm 17$ \\
$P$ range & 42 & 18 & 53 & 33 \\
\hline
\end{tabular}

$P$ indexes were calculated according to Townsend and Heuberg's equation $(n=18)$. The lower $P$ index, the higher expression of plant tolerance. Phenols were analysed in the season 2012/2013
'Hewo' and 'Magnat' had intermediate tolerance, with the first one being, on average, slightly more tolerant, so they were assigned as moderately tolerant and moderately sensitive in the present paper. $P$ index values were not stable among the years. The range between the most tolerant and the most sensitive line was the highest in the 3rd year of the experiment (2012-13), while the lowest was in the 2010/11 season (Table 1). Moreover, in the latter season, the line 'Hewo' appeared to be the most tolerant. Therefore, it was decided to compare phenolic concentrations with the average plant infection index $P$ of three seasons, as well as with the $P$ values of the 3 rd season performed simultaneously with the phenolic acids analyses.

\section{Phenolic acids in the non-hardened triticale seedlings and the correlation of their levels with the $M$. nivale tolerance}

Fifteen different phenolic acids (PhA) were detected in the non-hardened control plants (Supplement Table S2, S3). Six of them were found exclusively as free acids: p-Hb, 3,4Dhb, ChA, VA, GA and GeA. FA was the most abundant among the cell wall-bound PhA (WBPhA, Supplement Table S2), while RA showed, on average, the highest concentration among the free phenolic acids (FPhA, Supplement Table S2).

The mean concentration of the free FA, SiA, HvA, 3,4Dhb, BA, p-CA, CiA, SyA and SA measured in the sample from non-hardened seedlings had a significant negative correlation $(-0.7$ to -0.9$)$ with the average 2010-2013 triticale tolerance to the Microdochium nivale infection (Table 2). The same or very similar correlations were found between above phenolic acids concentration and the results of 2012/13 single tolerance test, with the exception of BA and SA levels, which were not correlated (Table 2). Additionally, the level of the free ChA was negatively correlated with the 2012/13 tolerance test, but not correlated with the average 2010-13 tests (Table 2). The correlation with tolerance was not significant for the free RA, p-Hb, VA, GA and GeA (Table 2). The concentration of the cell wall-bound FA,
SiA, p-CA, SyA and SA was also not correlated with the tolerance (Table 2). In contrast, the concentration of the cell wall-bound HvA and $\mathrm{CiA}$ was negatively correlated with tolerance, while the concentration of RA was the highest in the most tolerant line DH1 and positively correlated with pathogen tolerance (Table 2). The cell wall-bound BA level was negatively correlated only with the average tolerance (Table 2). The proportions of $\sum \mathrm{WBPhA} / \sum \mathrm{FPhA}$ and cell wall-bound/free $\mathrm{SiA}$ concentration were negatively correlated with the $M$. nivale tolerance (Table 3).

Depending on the genotype, the mean total amount of WBPhA was from 5.2 to 10.1 times higher in comparison to the mean total amount of FPhA; the highest proportion of the WBPhA to FPhA was found in the most tolerant line DH1, while the lowest in the most sensitive DH92 seedlings (Supplement Table S6). The proportion of WBPhA to FPhA was positively correlated with the $M$. nivale tolerance(Table S6), while the total amount of WBPhA showed no correlation (Table 2). A significant, strong, negative correlation with $M$. nivale tolerance was found for the total amount of FPhA (Table 2).

\section{Impact of cold-hardening on the phenolics content in the relation to the $M$. nivale tolerance of triticale seedlings}

Similarly to the non-hardened plants, 15 different PhA were detected in the cold-hardened ones and the same compounds were found exclusively as the free acids (Supplement Tables S2, S3). Again, FA was the most abundant among WBPhA (Supplement Table S3), while RA showed the highest concentration among FPhA (Supplement Table S2). After cold-hardening, the total concentration of both FPhA and WBPhA increased in seedlings of DH1 and DH92 plants, while it decreased in seedlings of both parents (Supplement Tables S2, S3). Moreover, in the cold-hardened plants of the particular genotypes, the percentage of the control non-hardened plants concentration was very similar in comparison to the total amounts of FPhA with WBPhA, so the described 


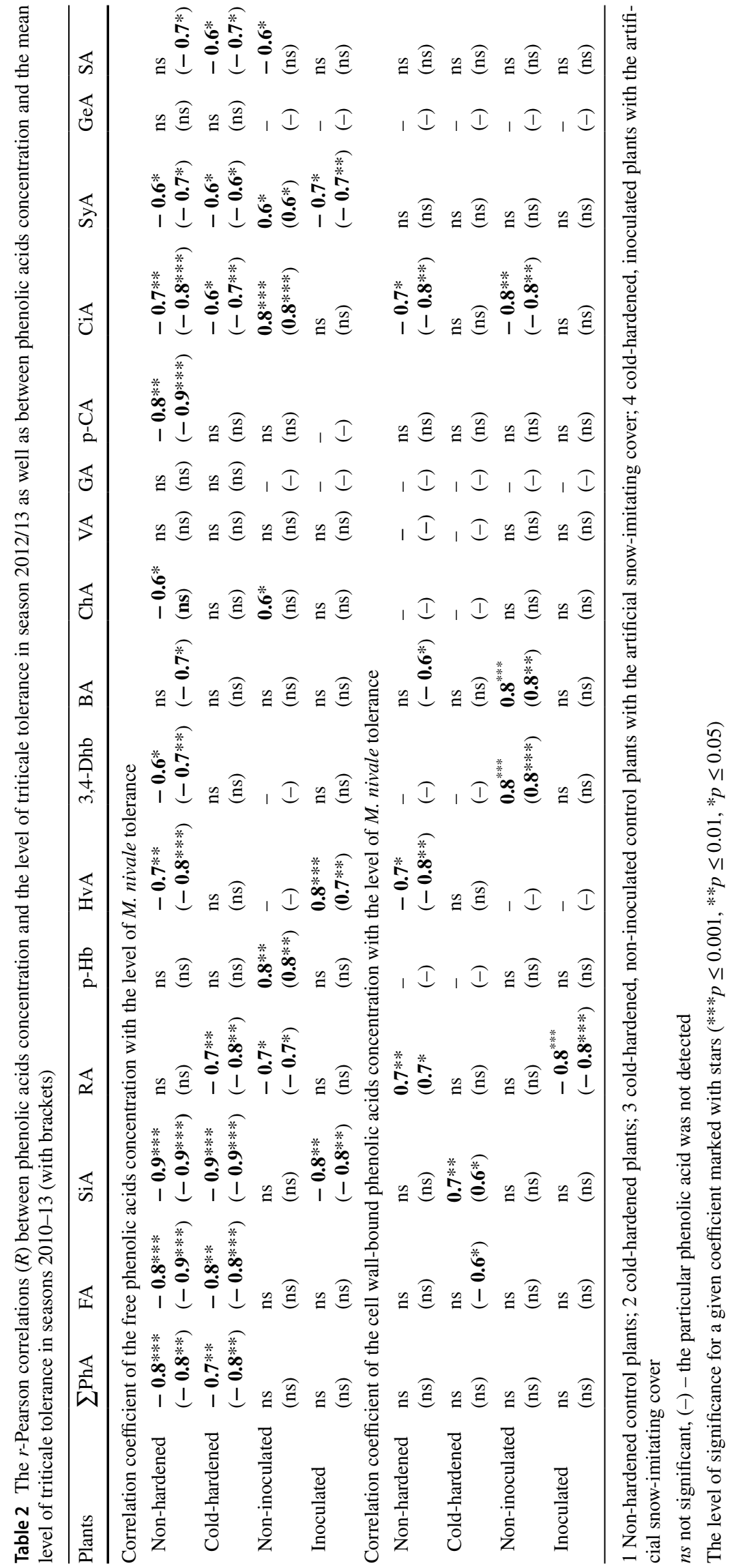


changes performed in the same proportion (Supplement Tables S2, S3).

The total amount of WBPhA was repeatedly not correlated with the $M$. nivale tolerance, while the significant, strong and negative correlation was found for the total amount of FPhA (Table 2).

After hardening, the negative correlation (from -0.6 to -0.9 ) between the phenolic concentrations and tolerance was maintained for the free FA, SiA, CiA, SyA and SA. The free RA correlation became also negative (Table 2). For the remaining $\mathrm{FPhA}$, the correlation was not significant, including previously correlated free $\mathrm{HvA}, 3,4-\mathrm{Dhb}, \mathrm{BA}$ and p-CA (Table 2).

After exposure to the low temperature, only two WBPhA showed significant correlation between their concentration and the plant tolerance, i.e. FA (negative) and $\mathrm{SiA}$ (positive), in contrast to being not significant in non-hardened plants (Table 2).

Depending on genotype, the total amount of WBPhA was 5.5 to 11 times higher in comparison to the amount of FPhA (Table S6). Again, the highest proportion of WBPhA to FPhA amounts was found in the most tolerant genotypesDH1 and 'Hewo', while the lowest was in the most sensitive DH92, and it was positively correlated with the M. nivale tolerance (Supplement Table S6).

After cold-hardening, the concentration in DH1 plants of total pool of WBPhA as well as cell wall-bound FA and $\mathrm{SiA}$ remarkably increased in respect to the control non-hardened ones of that genotype, in contrast to all remaining genotypes (Fig. 1). In contrast, only in DH92 cold-hardened plants was the increase of free RA in relation to the control visible (Fig. 1). The proportions of $\sum \mathrm{WBPhA} / \sum \mathrm{FPhA}$ and cell wall-bound/free $\mathrm{SiA}$ concentration were negatively correlated with the M. nivale tolerance after hardening (Table 3).

\section{Effect of snow-imitating covers on phenolics content}

In the cold-hardened seedlings with the artificial snowimitating cover, changes in concentration of the free (Supplement Table S4) and the cell wall-bound phenolic acids (Supplement Table S5) were more variable and larger in comparison to the effect of the cold-hardening (Supplement Tables S2, S3). The total pool of FPhA dropped after plant covering (Supplement Tables S2, S4). Four FPhA, identified in the non-hardened and the cold-hardened seedlings (HvA, 3,4-Dhb, GA and GeA) were not detected in plants with the artificial snow-imitating cover (Supplement Table S4). Additionally, correlation coefficients of the total pool of FPhA and the free FA and SiA lost their significance (Table 2, line 3). Free RA concentration remained negatively correlated with $M$. nivale tolerance (Table 2). The correlation coefficient of the free $\mathrm{p}-\mathrm{Hb}$ changed from not significant to the significantly positive value (Table 2), although its concentration dropped over ten times in comparison to values in cold-hardened plants (Supplement Table S4). Moreover, correlation coefficients of free $\mathrm{CiA}$ and SyA changed from negative to the significantly positive values (Table 2 , line 3). The level of free ChA and SA showed correlation only with 2012/2013 test-positive and negative, respectively (Table 2).

The concentration of total pool of WBPhA as well as cell wall-bound FA, 3,4-Dhb and BA dropped significantly in cold-hardened seedlings with the artificial snow-imitating cover in comparison to cold-hardened plants before covering (Supplement Tables S3, S5). That decrease was higher for sensitive genotypes, but it was correlated with tolerance only for cell wall-bound 3,4-Dhb and BA (0.8) (Table 2). It is worth noticing that the concentration of cell wall-bound $\mathrm{SiA}$ and CiA dropped to very low values (Supplement Table S5) and the second one showed negative correlation with tolerance (Table 2). Four cell wall-bound phenolic acids, which were not detected before covering, were identified in coldhardened covered plants: pHb, 3,4-Dhb, ChA and VA (Supplement Table S5).

Depending on genotype, the total amount of WBPhA was from 4.9 to 6.9 times higher in comparison to the amount of FPhA (Supplement Table S6). Again, the highest proportion of WBPhA to FPhA was found in the seedlings of the most tolerant genotype-DH1, but it was not correlated with the plant tolerance (Table 3; Supplement Table S6). Under the covers, the proportion of cell wall-bound/free CiA concentration was positively correlated with the $M$. nivale tolerance (Table 3).

\section{Effect of Microdochium nivale infection on phenolics content}

In cold-hardened, inoculated seedlings with the artificial snow-imitating cover, the same free phenolic acids were detected as in non-inoculated ones with two exceptions (HvA and 3,4-Dhb) that were exclusively present after inoculation (Supplement Table S4).

The general concentration of FPhA increased after plant inoculation in comparison to non-inoculated plants (Supplement Table S4), but it remained uncorrelated with plant tolerance (Table 2). Depending on genotype, the total amount of WBPhA was from 1.8 to 3.2 times higher in comparison to the amount of FPhA (Supplement Table S6). As in previous experimental measurements, the proportion of WBPhA to $\mathrm{FPhA}$ in the most tolerant $\mathrm{DH} 1$ was higher in comparison to that observed for the most sensitive DH92; however, it was not correlated with the plant tolerance (Table 2).

Correlation coefficients of free $\mathrm{RA}, \mathrm{p}-\mathrm{Hb}, \mathrm{ChA}$ and $\mathrm{CiA}$ concentration with tolerance lost their significance in inoculated seedlings, in contrast to non-inoculated plants (Table 2). The other two FPhA (SiA and HvA) changed 
correlation into significant (negative and positive, accordingly). After plant covering, free HvA was detected only in inoculated seedlings of the most tolerant DH1 genotype (Supplement Table S4). The correlation coefficient of free SyA changed from positive to a significantly negative value (Table 2, line 4). The concentration of the remaining free phenolics was not correlated with plant tolerance (Table 2).

General concentration of WBPhA also increased after plant inoculation in comparison to the non-inoculated plants (Supplement Table S5), but the correlation remained statistically insignificant (Table 2). The concentration of several individual acids, e.g., cell wall-bound FA, SiA and CiA, increased after plant inoculation in comparison to non-inoculated seedlings (Supplement Table S5), but their concentration was also not correlated with plant tolerance (Table 2). After inoculation, 3,4-Dhb was detected only in cv. Hewo seedlings (Supplement Table S5) and its correlation with seedlings tolerance dropped into not significant (Table 2). In contrast, the concentration of RA changed its correlation with plant tolerance from not significant into negative, and it was the only cell wall-bound acid correlated with the level of tolerance after inoculation (Table 2). In contrast to the all remaining plants, in cold-hardened, inoculated seedlings with the artificial snow-imitating cover, cell wall-bound $\mathrm{PhA}$ did not show any positive correlation with the plant susceptibility (Table 2).

After inoculation, the concentration of total FPhA, total WBPhA (Table 3), cell wall-bound FA, SiA and $\mathrm{CiA}$ as well as free RA and ChA remarkably increased in respect to the control non-inoculated plants of all genotypes, most prominently in sensitive DH92 plants (Fig. 2). Triticale genotype, seedlings treatment and the interaction of these factors significantly $(p \leq 0.001)$ influenced the content of all detected free phenolic acids (with the exception of $\mathrm{CiA}$ ) as well as on the total amount of free phenolic acids $\sum \mathrm{FPhA}$ (Supplement Table S6). Similarly, all independent factors and their interaction significantly influenced the content of most of the cell wall-bound phenolic acids: SiA, RA, HvA, 3,4Dhb, BA, ChA, VA, p-CA, CiA, SyA and SA (Supplement Table S6). The total amount of cell wall-bound phenolic acids was significantly influenced by genotype and treatment but not by interaction, while only treatment had a significant effect on the content of cell wall-bound FA and p-Hb (Supplement Table S6).

Table 3 The proportion between total concentration of cell-wall bound phenolic acids (WBPhA) and free phenolic acids (FPhA) in all above soil level parts of hexaploid triticale seedlings growing in different experimental conditions

\begin{tabular}{|c|c|c|c|c|c|}
\hline Treatment & DH1 & Hewo & Magnat & DH92 & $R^{2012 / 13}\left(R^{2012 / 13}\right)$ \\
\hline \multicolumn{6}{|l|}{ The proportion of $\sum \mathrm{WBPhA} / \sum \mathrm{FPhA}$ concentration } \\
\hline Non-hardened control plants & $10.1 \pm 0.6$ & $10.1 \pm 0.9$ & $6.8 \pm 0.7$ & $5.2 \pm 0.9$ & $\mathbf{0 . 8}^{* * *}\left(0.9^{* * *}\right)$ \\
\hline Cold-hardened plants & $11.0 \pm 3.6$ & $10.0 \pm 1.6$ & $6.0 \pm 1.2$ & $5.5 \pm 0.2$ & $0.7 * *(0.8 * *)$ \\
\hline $\begin{array}{l}\text { Cold-hardened control plants with the artificial snow- } \\
\text { imitating cover }\end{array}$ & $6.9 \pm 0.5$ & $5.3 \pm 0.7$ & $4.9 \pm 0.7$ & $6.1 \pm 1.1$ & ns (ns) \\
\hline $\begin{array}{l}\text { Cold-hardened, inoculated plants with the artificial snow- } \\
\text { imitating cover }\end{array}$ & $2.5 \pm 0.6$ & $1.8 \pm 0.5$ & $3.2 \pm 0.7$ & $1.8 \pm 0.3$ & ns (ns) \\
\hline \multicolumn{6}{|l|}{ The proportion of cell wall-bound/free $\mathrm{SiA}$ concentration } \\
\hline Non-hardened control plants & $19.6 \pm 3.5$ & $39.2 \pm 6.2$ & $52.2 \pm 8.5$ & $112.1 \pm 34.4$ & $\mathbf{0 . 8} \mathbf{8}^{* * *}\left(\mathbf{0 . 9} \mathbf{9}^{* * *}\right)$ \\
\hline Cold-hardened plants & $14.7 \pm 3.8$ & $35.2 \pm 7.1$ & $40.8 \pm 8.1$ & $64.1 \pm 7.4$ & $0.8 * * *(0.8 * *)$ \\
\hline $\begin{array}{l}\text { Cold-hardened control plants with the artificial snow- } \\
\text { imitating cover }\end{array}$ & $67.5 \pm 11.4$ & $105.2 \pm 15.9$ & $100.1 \pm 15.3$ & $55.6 \pm 10.5$ & ns (ns) \\
\hline $\begin{array}{l}\text { Cold-hardened, inoculated plants with the artificial snow- } \\
\text { imitating cover }\end{array}$ & $60.9 \pm 13.3$ & $84.2 \pm 10.4$ & $69.9 \pm 12.5$ & $206.5 \pm 24.6$ & ns (ns) \\
\hline \multicolumn{6}{|l|}{ The proportion of cell wall-bound/free CiA concentration } \\
\hline Non-hardened control plants & $2.2 \pm 1.3$ & $1.8 \pm 0.4$ & $1.8 \pm 0.2$ & $1.8 \pm 0.3$ & ns (ns) \\
\hline Cold-hardened plants & $2.9 \pm 0.5$ & $4.9 \pm 1.1$ & $1.0 \pm 0.2$ & $1.4 \pm 0.4$ & ns (ns) \\
\hline $\begin{array}{l}\text { Cold-hardened control plants with the artificial snow- } \\
\text { imitating cover }\end{array}$ & $1.4 \pm 0.0$ & $2.7 \pm 0.6$ & $5.5 \pm 2.0$ & $5.9 \pm 0.4$ & $-\mathbf{0 . 8} * * *(-0.9 * * *)$ \\
\hline $\begin{array}{l}\text { Cold-hardened, inoculated plants with the artificial snow- } \\
\text { imitating cover }\end{array}$ & $1655.9 \pm 662.5$ & - & $34.8 \pm 31.6$ & $66.9 \pm 24.8$ & ns (ns) \\
\hline
\end{tabular}

Values present mean \pm standard deviation $(n=6) . R$ the $r$-Pearson correlation coefficient between the phenolic acids content and the level of $M$. nivale tolerance

$n s$ not significant

The level of significance for a given coefficient marked with stars $(* * * p \leq 0.001, * * p \leq 0.01, * p \leq 0.05)$ 


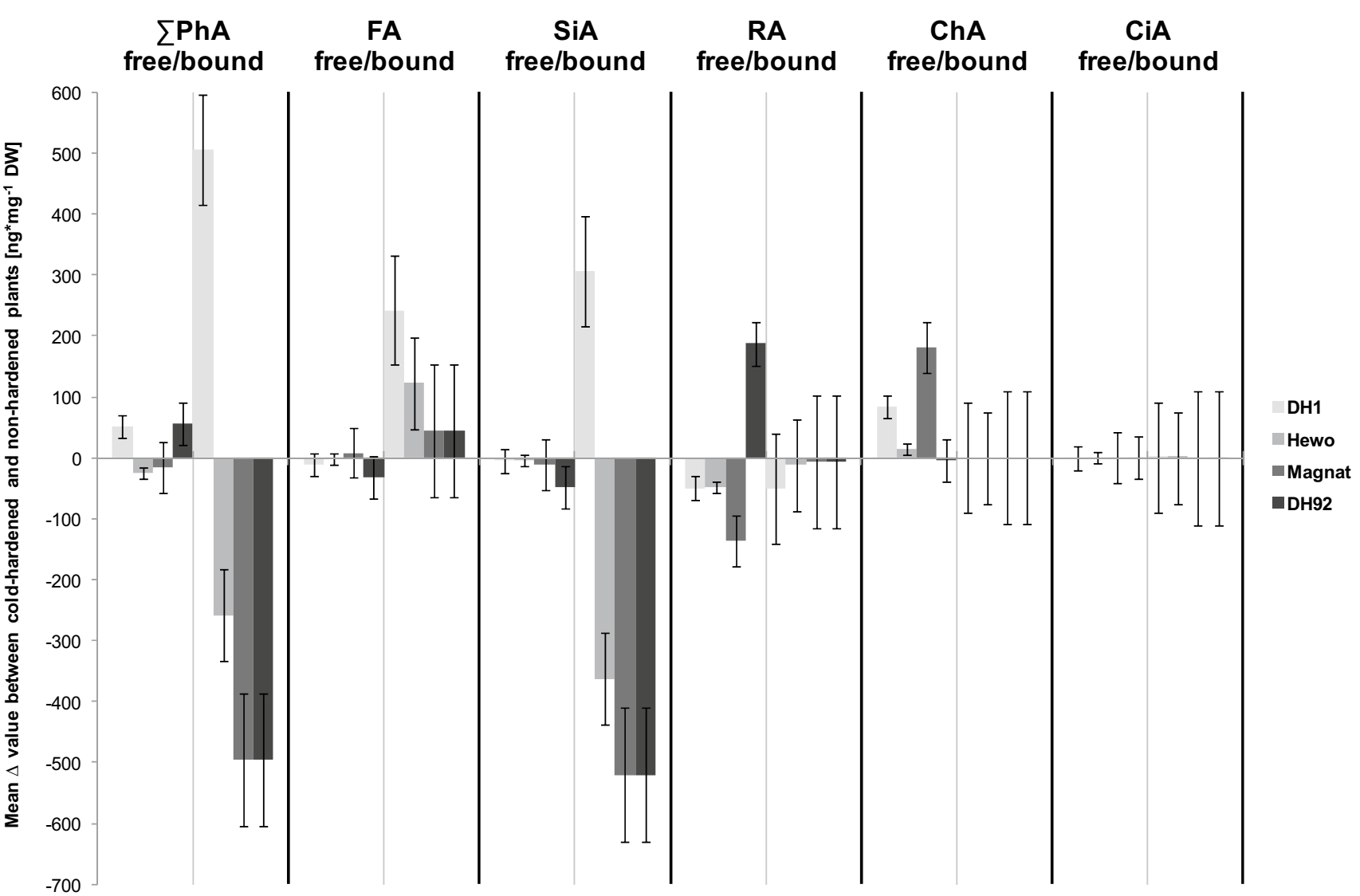

Fig. 1 Changes in concentration of the most prominent free and cell wall-bound phenolic acids in cold-hardened winter triticale seedlings in respect to the control non-hardened ones. Values obtained present mean difference between cold-hardened and control plants [ng

\section{Discussion}

In the present research, as many as 15 different phenolic acids were detected, with the better representation of the free compounds in comparison to any previous research, according to our knowledge. In all investigated plants, FA was the most abundant among the WBPhA and all detected phenolics, while RA showed the highest concentration among the FPhA pool. Similarly, FA was the predominant phenolic compound found in many other studies, e.g., in triticale (Hosseinian and Mazza 2009; Hura et al. 2009), wheat (Olenichenko et al. 2006; Southerton and Deverall 1990), durum wheat (Nicoletti et al. 2013) and spelt (Gawlik-Dziki et al. 2012).

The results strongly suggest that the abundance of specific phenolic acids was affected by plant genotype, cold hardening and infection by the pink snow mould pathogen. In our work, we found relevant changes in the plant phenolic acid profile as the response to the modification of the growing conditions. It indicated that both the quantitative and qualitative contents of individual free and cell wall-bound $\left.\mathrm{mg}^{-1} \mathrm{DW}\right] \pm$ standard error $(n=6) . P h A$ phenolic acids, $F A$ ferulic acid, $\mathrm{SiA}$ sinapic acid, $R A$ rosmarinic acid, $C h A$ chlorogenic acid, $C i A$ trans-cinnamic acid

phenolic acids in winter triticale seedlings were significantly influenced by plant genotype and culture conditions, e.g., low temperature, artificial snow-imitating covers and Microdochium nivale fungal infection. The high impact of pathogen infection on the composition of plant phenolics was reported before (Bollina et al. 2011; Siranidou et al. 2002; Southerton and Deverall 1990). The authors connected this phenomenon with their role in lignifications but also with their antioxidant potential and ROS scavenging ability. Low temperature alone also modified phenolic acid content in the experiments of Lattanzio et al. (2006) and Koc et al. (2010).

In our studies, the total amount of WBPhA always had a higher concentration than the total concentration of FPhA. Moreover, it is very interesting that the proportion of their concentration was higher in the most tolerant genotype (DH1) than in the most sensitive (DH92) one in all experimental points, especially in non-hardened and cold-hardened seedlings. Additionally, a significant, strong, and negative correlation with $M$. nivale tolerance for the total amount $\mathrm{FPhA}$ as well as for many individual free phenolic acids was found in cold-hardened seedlings and in control plants. 


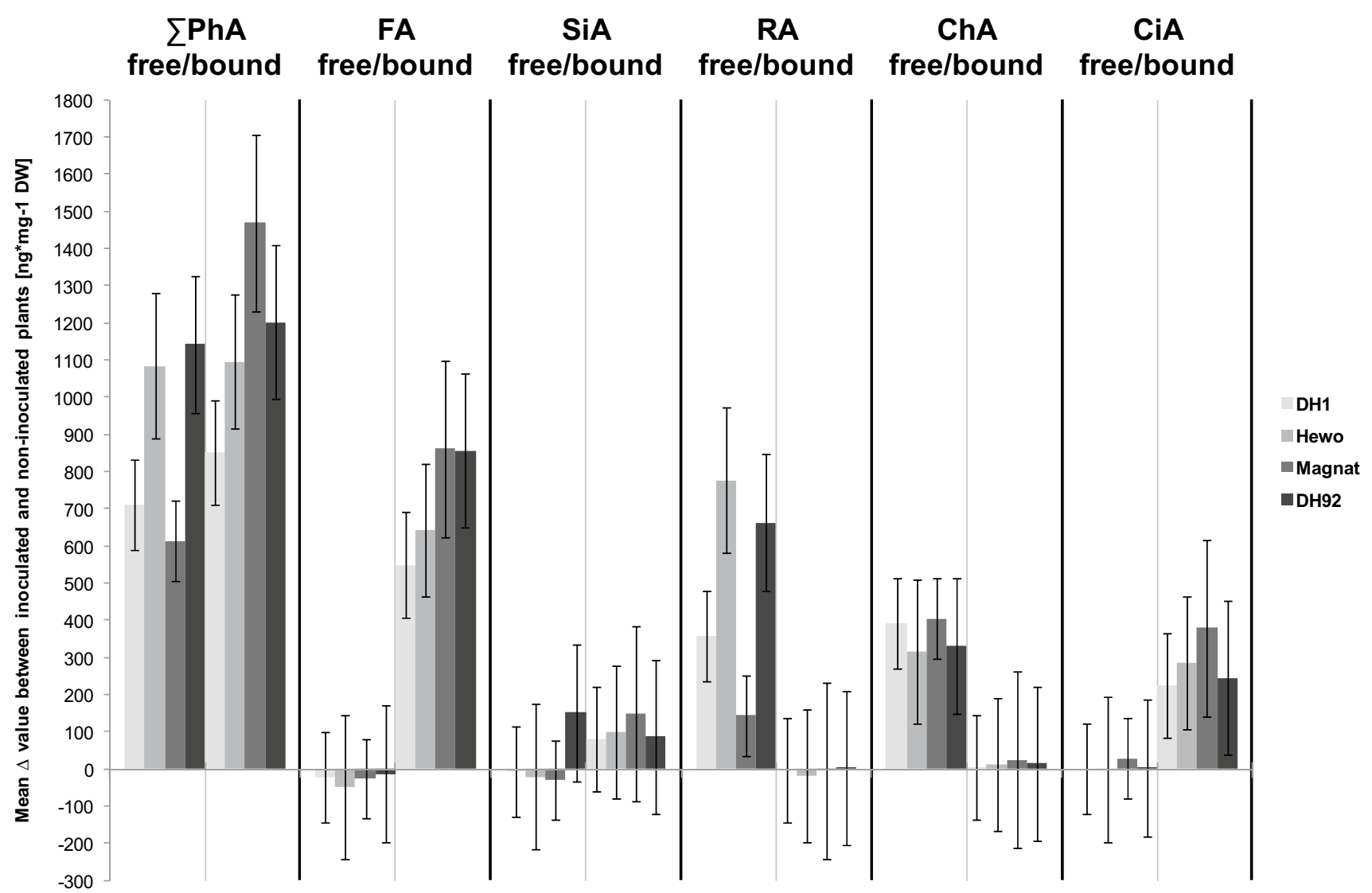

Fig. 2 Changes in concentration of the most prominent free and cell wall-bound phenolic acids in cold-hardened, inoculated winter triticale seedlings with the artificial snow-imitating cover in respect to the cold-hardened control non-inoculated plants with the artificial snowimitating cover. Values obtained present mean difference between inoculated winter triticale seedlings with the artificial snow-imitating cover in respect to the cold-hardened control non-inoculated plants with the artificial snow-imitating cover $\left[\mathrm{ng} \mathrm{mg}^{-1} \mathrm{DW}\right] \pm$ standard error $(n=6)$. PhA phenolic acids, $F A$ ferulic acid, SiA sinapic acid, $R A$ rosmarinic acid, $C h A$ chlorogenic acid, $C i A$ trans-cinnamic acid
Furthermore, in non-hardened and cold-hardened plants, none of the free phenolic acids showed a positive correlation with plant tolerance. Those results could suggest that, in winter triticale seedlings, free phenolic compounds are not directly connected with a cold-induced pink snow mould tolerance. However, 10 out of $15 \mathrm{FPhA}$ had higher levels under the low temperature in some plants in relation to adequate non-hardened control. Additionally, in cold-hardened seedlings, the percentage of free HvA, 3,4-Dhb and BA concentrations in control plants was positively correlated with triticale tolerance. Other authors also observed phenolic acid accumulation in HPLC analysed ethanol extracts of leaves of winter and spring wheat after exposure to cold (Moheb et al. 2011; Olenichenko and Zagoskina 2005; Olenichenko et al. 2006).

During our further studies, under the abiotic stress of combined low temperature and artificial snow-imitating cover with no additional inoculation, the concentration of FPhA decreased in comparison to uncovered plants. Nevertheless, in contrast to plants before covering, the concentration of free $\mathrm{p}-\mathrm{Hb}, \mathrm{ChA}, \mathrm{CiA}$ and $\mathrm{SyA}$ was positively correlated with plant tolerance. After plant inoculation, the general concentration of FPhA increased in comparison to non-inoculated plants and still remained not correlated with the tolerance. In contrast, free HvA was detected only within inoculated seedlings of most tolerant DH1 genotype thus, as an exception, positively correlated with the plant tolerance. In cold-hardened, inoculated plants with the artificial snow-imitating cover, the percentage of the control concentration of free RA and SA was positively correlated with triticale tolerance. Such conditions were not previously studied for the mentioned free phenolic acids content.

Unexpectedly, in the whole experiment, the total amount of WBPhA was not correlated with triticale susceptibility to Microdochium nivale infection. The cell wall-bound SiA was cold-accumulated only in seedlings of the most tolerant genotype; and, after exposure to the low temperature, its concentration was positively correlated with the plant tolerance. In cold-hardened seedlings, the percentage of 
control plants cell wall-bound HvA and BA concentration was positively correlated with triticale tolerance, similarly to their free forms. The total concentration of WBPhA and the concentration of several individual acids (cell wall-bound $\mathrm{FA}, \mathrm{SiA}$, and $\mathrm{CiA}$ ) also increased after plant inoculation in comparison to non-inoculated plants, but their concentration was not correlated with plant susceptibility. However, both in cold-hardened as well as cold-hardened, inoculated plants with the artificial snow-imitating cover, the percentage of the control concentration of cell wall-bound CiA was positively correlated with triticale tolerance. The concentration of cell wall-bound 3,4-Dhb and BA was positively correlated with triticale tolerance only in non-inoculated, covered plants.

Other authors also observed that the cell wall-bound phenolic acids, which accumulated in cells undergoing a hypersensitive response, were associated with the tolerance of Lr28-bearing wheat to the leaf rust fungus (Southerton and Deverall 1990). The metabolic changes in level of foliar phenolics and increased PAL activity during cold acclimation in androgenic forms of Festulolium were observed in frost-tolerant and snow mould-tolerant (cross-tolerant) genotypes (Pociecha et al. 2008). A rise of the cell wallbound phenolics concentration was also correlated with the productivity of triticale (Hura et al. 2012) and rice (Quan et al. 2016) under soil drought. Furthermore, during the microscopic analysis, the cell wall-phenolics accumulated in sites of M. nivale invasion in winter triticale (Dubas et al. 2011), Lolium perenne (Dubas et al. 2010) and winter rye (Żur et al. 2011) seedlings.

When summarizing both cold-hardening and inoculation results, 2 out of 12 detected cell wall-bound acids could be indicated for further studies as potentially related with the increased snow mould tolerance of winter triticale seedlings: $\mathrm{SiA}$ and $\mathrm{CiA}$. The first of them, $\mathrm{SiA}$, was cold-accumulated only in seedlings of the most tolerant DH1 line (doubled concentration), while its concentration substantially decreased in plants of all remaining genotypes. However, under the artificial snow-imitating covers, it always had a similar level between DH1 and DH92 plants, despite the multiple increase of its concentration after plant inoculation. This could indicate that SiA might have a potential role only in cold-mediated plant preparation before pathogenesis. According to literature reviewed by Nićiforović and Abramovič (2014), sinapic acid is one of the most common hydroxycinnamic acids, and it is widespread in plants; moreover, it can act as an antioxidant with a higher efficacy than that of ferulic acid and similar to that of caffeic acid. Sinapic acid also shows antimicrobial activity in in vitro conditions (Engels et al. 2012; Maddox et al. 2010). According to our knowledge, its concentration has not been analysed before in triticale. Here, we postulate that better plant conditions before infection due to the antioxidant and antimicrobial functions of SiA could be the cause of better pink snow mould survival.
The second of important identified compounds, the cell wall-bound CiA, was also cold-accumulated only in tolerant genotypes (DH1, cv. Hewo) and its concentration strongly raised after plant inoculation. We suggest that it may be important for cell wall construction and rebuilding under winter stresses in triticale seedlings. This hypothesis could also partly explain the decrease of the free $\mathrm{CiA}$ from the level observed in tolerant genotypes during the inoculation experiment. As in our research, the $\mathrm{CiA}$ was indicated as a tolerance biomarker to the Fusarium head blight (FHB) of the bread wheat (Hamzehzarghani 2007). Similarly to our results, in Janda et al. (2007) analysis, the level of the cell wall-bound $\mathrm{CiA}$ increased during cold-hardening at $5{ }^{\circ} \mathrm{C}$ in leaves of frost-tolerant winter wheat. The other potentially important phenolics identified by us include the following: free and cell wall-bound RA, HvA, 3,4-Dhb and BA as well as free $\mathrm{p}-\mathrm{Hb}, \mathrm{ChA}$, SyA and SA.

Apart from an eventual role of described individual phenolic acids, on the basis of our results, we state the thesis that, at least as the impact of separate molecules, the proportion between the total levels of cell wall-bound and free phenolic compounds could be very important for plant survival under abiotic and biotic stresses. Additionally, the relative level of $\mathrm{PhA}$ after the stress exposure, in respect to adequate control, might be as important as their absolute level.

Author contribution statement GG-P experiment design and getting funding, plant material selection, culture, inoculation and sampling, statistics and paper writing. MD sample preparation and HPLC analysis. IW plant material culture, inoculation and sampling. KW plant material culture, inoculation and sampling. MD plant material culture, inoculation and sampling. MW methods and text consulting.

Acknowledgements The present work was financed by the National Science Centre, Project no. N N310 140239: "Application of DH lines for early selection of triticale ( $x$ Triticosecale Wittm.) resistance to snow mould caused by Microdochium nivale (Fr., Samuels and Hallett)", Poland.

\section{Compliance with ethical standards}

Conflict of interest There are no financial or personal conflicts of interest by the authors.

Open Access This article is distributed under the terms of the Creative Commons Attribution 4.0 International License (http://creativeco mmons.org/licenses/by/4.0/), which permits unrestricted use, distribution, and reproduction in any medium, provided you give appropriate credit to the original author(s) and the source, provide a link to the Creative Commons license, and indicate if changes were made. 


\section{References}

Aristimuño Ficoseco ME, Vattuone MA, Audenaert K, Catalán CAN, Sampietro DA (2014) Antifungal and antimycotoxigenic metabolites in Anacardiaceae species from northwest Argentina: isolation, identification and potential for control of Fusarium species. J Appl Microbiol 116(5):1262-1273. https://doi.org/10.1111/ jam. 12436

Assabgui RA, Reid LM, Hamilton RL, Arnason JT (1993) Correlation of kernel (E)-ferulic acid content of maize with resistance to Fusarium graminearum. Phytopathology 83:949-953

Bateman GL (2008) Control of seed-borne Fusarium nivale on wheat and barley by organomercury seed treatment. Ann Appl Biol 83(2):245-250. https://doi.org/10.1111/j.1744-7348.1976.tb006 03. $\mathrm{x}$

Bollina V, Kushalappa AC (2011) In vitro inhibition of trichothecene biosynthesis in Fusarium graminearum by resistance-related endogenous metabolites identified in barley. Mycology 2(4):291296. https://doi.org/10.1080/21501203.2011.604354

Boutigny AL, Atanasova-Pénichon V, Benetm M, Barreau C, RichardForget F (2010) Natural phenolic acids from wheat bran inhibit Fusarium culmorum trichothecene biosynthesis in vitro by repressing Tri gene expression. Eur J Plant Pathol 127(2):275286. https://doi.org/10.1007/s10658-010-9592-2

Dubas E, Marzec K, Płażek A (2010) Cytological studies on Microdochium nivale infection in Lolium perenne (L.) plants. Zeszyty Problemowe Postępów Nauk Rolniczych PAN 545:389-401

Dubas E, Gołębiowska G, Żur I, Wędzony M (2011) Microdochium nivale (Fr., Samuels \& Hallett): cytological analysis of the infection process in triticale (x Triticosecale Wittm.). Acta Physiol Plant 33(2):529-537. https://doi.org/10.1007/s11738-010-0576-9

Dyda M, Wąsek I, Tyrka M, Wędzony M, Szechyńska-Hebda M (2018) Local and systemic regulation of PSII efficiency in triticale infected by the hemibiotrophic pathogen Microdochium nivale. Physiol Plant. https://doi.org/10.1111/ppl.12760

Engelharclt G, Koeniger M, Prei $\beta$ U (2002) Influence of wheat phenolic acids on Fusarium Head Blight resistance and Deoxynivalenol accumulation. Mycotoxin Res 18(Suppl 1):100-103. https://doi. org/10.1007/BF02946073

Engels C, Schieber A, Gänzle MG (2012) Sinapic acid derivatives in defatted oriental mustard (Brassica juncea L.) seed meal extracts using UHPLC-DAD-ESI-MSn and identification of compounds with antibacterial activity. Eur Food Res Technol 234:535-542. https://doi.org/10.1007/s00217-012-1669-z

Gaudet DA, Wang Y, Frick M, Puchalski B, Penniket C, Ouellet T, Robert L, Singh J, Laroche A (2011) Low temperature induced defence gene expression in winter wheat in relation to resistance to snow moulds and other wheat diseases. Plant Sci 180(1):99_ 110. https://doi.org/10.1016/j.plantsci.2010.07.023

Gawlik-Dziki U, Świeca M, Dziki D (2012) Comparison of phenolic acids profile and antioxidant potential of six varieties of spelt (Triticum spelta L.). J Agr Food Chem 18:4603-4612. https:// doi.org/10.1021/jf3011239

Gołębiowska G, Wędzony M (2009) Cold-hardening of winter triticale ( $x$ Triticosecale Wittm.) results in increased resistance to pink snow mould Microdochium nivale (Fr., Samuels \& Hallett) and genotype-dependent chlorophyll fluorescence modulations. Acta Physiol Plant 31(6): 12-19. https://doi.org/10.1007/s1173 8-009-0357-5

Gołębiowska G, Wędzony M, Płażek A (2011) The responses of proand antioxidative systems to cold-hardening and pathogenesis differs in triticale (x Triticosecale Wittm.) seedlings susceptible or resistant to pink snow mould (Microdochium nivale Fr., Samuels \& Hallett). J Phytopathol 159(1):19-27. https://doi.org/10.111 $1 /$ j.1439-0434.2010.01712.x
Hamzehzarghani H (2007) Metabolic profiling and multivariate analysis to phenotype cultivars of wheat varying in resistance to fusarium head blight. Dissertation, Department of Plant Science, McGill University, Montreal, Quebec, Canada

Hanifei M, Dehghani H, Choukan R (2013) The role of antioxidant enzymes and phenolic compounds in disease resistance to Fusarium oxysporum f. sp. Melonis race 1.2. Int J Agron Plant Prod 4(8):1985-1996

Hoagland DR, Arnon DI (1938) A water culture method for growing plants without soil. Circ Univ Calif Agric Exp Stn 347:32

Hosseinian FS, Mazza G (2009) Triticale bran and straw: potential new sources of phenolic acids, proanthocyanidins, and lignans. J Funct Foods 1(1):57-64. https://doi.org/10.1016/j.jff.2008.09.009

Hudec K, Bokor P (2002) Field patogenicity of Fusarium culmorum, Fusarium equiseti and Microdochium nivale on triticale. Physiol Plant 115(1):101-110

Hura T, Hura K, Grzesiak S (2008) Contents of total phenolics and ferulic acid, and PAL activity during water potential changes in leaves of maize single-cross hybrids of different drought tolerance. J Agron Crop Sci 194(2):104-112. https://doi.org/10.1111/j.1439037X.2008.00297.x

Hura T, Hura K, Grzesiak S (2009) Leaf dehydration induces different content of phenolics and ferulic acid in drought-resistant and -sensitive genotypes of spring triticale. Z Naturforsch 64c:85-95. https://doi.org/10.1515/znc-2009-1-215

Hura T, Hura K, Dziurka K, Ostrowska A, Bączek-Kwinta R, Grzesiak MT (2012) An increase in the content of cell wall-bound phenolics correlates with the productivity of triticale under soil drought. J Plant Physiol 169:1728-1736. https://doi.org/10.1016/j. jplph.2012.07.012

Ivanov S, Miteva L, Alexieva V, Karjin H, Karanov E (2004) Alterations in some oxidative parameters in susceptible and resistant wheat plants infected with Puccinia recondita f.sp. tritici. J Plant Physiol 162(3):275-279. https://doi.org/10.1016/j.jplph .2004 .07 .010

Janda T, Szalai G, Leskó K, Yordanova R, Apostol S, Petrova Popova L (2007) Factors contributing to enhanced freezing tolerance in wheat during frost hardening in the light. Phytochemistry 68(12):1674-1682. https://doi.org/10.1016/j.phyto chem.2007.04.012

Király L, Barna B, Király Z (2007) Plant resistance to pathogen infection: forms and mechanisms of innate and acquired resistance. J Phytopathol 155(7-8):385-396(12). https://doi.org/10.111 1/j.1439-0434.2007.01264.x

Koc E, Islek C, Ustun AS (2010) Effect of cold on protein, proline, phenolic compounds and chlorophyll content of two pepper (Capsicum annuum $\mathrm{L}$.) varieties. J Sci 23(1):1-6

Kumar M, Yadav V, Tuteja N, Johri AK (2009) Antioxidant enzyme activities in maize plants colonized with Piriformospora indica. Microbiology 155: 780-790. https://doi.org/10.1099/mic.0.01986 9-0

Lattanzio V, Lattanzio VMT, Cardinali A (2006) Role of phenolics in the resistance mechanisms of plants against fungal pathogens and insects. Adv Res Phytochem 66:23-67

Leroux P, Lanen C, Fritz R (2006) Similarities in the antifungal activities of fenpiclonil, iprodione and tolclofos-methyl against Botrytis cinerea and Fusarium nivale. Pestic Sci 36(3):255-261. https:// doi.org/10.1002/ps.2780360312

Leszczyński B (1985) Changes in phenols content and metabolism in leaves of susceptible and resistant winter wheat cultivars infested by Rhopalosiphum padi (L.) (Hom., Aphididae). J Appl Entomol 100(1-5):343-348

Maddox CE, Laur LM, Tian L (2010) Antibacterial activity of phenolic compounds against the phytopathogen Xylella fastidiosa. Curr Microbiol 60:53-58. https://doi.org/10.1007/s00284-009-9501-0 
McKeehen JD, Busch RH, Fulcher RG (1999) Evaluation of wheat (Triticum aestivum L.) phenolic acids during grain development and their contribution to Fusarium resistance. J Agr Food Chem 47(4):1476-1482. https://doi.org/10.1021/jf980896f

Miedaner T, Höxter H, Geiger HH (2011) Development of a resistance test for winter rye to snow mold (Microdochium nivale) under controlled environment conditions in regard to field inoculations. Can J Bot 71(1):136-144. https://doi.org/10.1139/b93-015

Miedes E, Vanholme R, Boerjan W, Molina A (2014) The role of the secondary cell wall in plant resistance to pathogens. Front Plant Sci 05 August 2014. https://doi.org/10.3389/fpls.2014.00358

Moheb A, Ibrahim RK, Roy R, Sarhan F (2011) Changes in wheat leaf phenolome in response to cold acclimation. Phytochemistry 72(18):2294-2307. https://doi.org/10.1016/j.phyto chem.2011.08.021

Nakajima T, Abe J (2011) Environmental factors affecting expression of resistance to pink snow mold caused by Microdochium nivale in winter wheat. Can J Bot 74(11):1783-1788. https://doi. org/10.1139/b96-215

Naz R, Bano A, Wilson NL, Guest D, Roberts TH (2014) Pathogenesis-Related protein expression in the apoplast of wheat leaves protected against leaf rust following application of plant extracts. Phytopathology 104(9):933-944. https://doi.org/10.1094/PHYTO $-11-13-0317-R$

Ng G, Seabolt S, Zhang C, Salimian S, Watkins TA, Lu H (2011) Genetic dissection of salicylic acid-mediated defence signalling networks in Arabidopsis. Genetics 189(3):851-859. https://doi. org/10.1534/genetics.111.132332

Nicholson RL, Hammerschmidt R (1992) Phenolic compounds and their role in disease resistance. Annu Rev Phytopathol 30:369389. https://doi.org/10.1146/annurev.py.30.090192.002101

Nićiforović N, Abramovič H (2014) Sinapic acid and its derivatives: natural sources and bioactivity. Compr Rev Food Sci Food Saf 13(1):34-51. https://doi.org/10.1111/1541-4337.12041

Nicoletti I, Martini D, De Rossi A, Taddei F, D’Egidio MG, Corradini D (2013) Identification and quantification of soluble free, soluble conjugated and insoluble bound phenolic acids in durum wheat (Triticum turgidum L. var. durum) and derived products by RP-HPLC on a semimicro separation scale. J Agric Food Chem 61(48):11800-11807. https://doi.org/10.1021/jf403568c

Nielsen LK, Justesen AF, Jensen JD, Jørgensen LN (2013) Microdochium nivale and Microdochium majus in seed samples of Danish small grain cereals. Crop Prot 43:192-200. https://doi. org/10.1016/j.cropro.2012.09.002

Olenichenko NA, Zagoskina NV (2005) Response of winter wheat to cold: production of phenolic compounds and L-Phenylalanine Ammonia Lyase activity. Appl Biochem Micro 41(6): 600-603. https://doi.org/10.1007/s10438-005-0109-2

Olenichenko NA, Ossipov VI, Zagoskina NV (2006) Effect of cold hardening on the phenolic complex of winter wheat leaves. Russ J Plant Physiol 53(4): 495-500. https://doi.org/10.1134/S1021 443706040108

Parry DW, Rezanoor HN, Pettitt TR, Hare MC, Nicholson P (2008) Analysis of Microdochium nivale isolates from wheat in the UK during 1993. Ann Appl Biol 126(3):449-455. https://doi. org/10.1111/j.1744-7348.1995.tb05379.x

Płażek A, Hura K, Żur I, Niemczyk E (2003) Relationship between frost tolerance and cold-induced resistance of spring barley, meadow fescue and winter oilseed rape to fungal pathogens. J Agron Crop Sci 189(5):333-340. https://doi.org/10.1046/j.1439037X.2003.00052.X

Pociecha E, Płażek A, Janowiak F, Zwierzykowski Z (2008) ABA level, proline and phenolic concentration, and PAL activity induced during cold acclimation in androgenic Festulolium forms with contrasting resistance to frost and pink snow mould (Microdochium nivale). Physiol Mol Plant Pathol 73(6):126-132. https://doi. org/10.1016/j.pmpp.2009.03.005

Prasad D, Singh A, Singh KP, Bist S, Tewari A, Singh UP (2010) The role of phenolic compounds in disease resistance in geranium. Arch Phytopathol Plant Prot 43(7):615-623. https://doi. org/10.1080/03235400801972467

Quan NT, Anh LH, Khang DT, Tuyen PT, Toan NP, Minh TN, Bach DT, Ha PTT, Elzaawely AA, Khanh TD, Trung KH, Xuan TD (2016) Involvement of secondary metabolites in response to drought stress of rice (Oryza sativa L.). Agriculture 6(2):23. https ://doi.org/10.3390/agriculture6020023

Rastogi N, Goh KS, Horgen L, Barrow WW (1998) Synergistic activities of antituberculous drugs with cerulenin and trans-cinnamic acid against Mycobacterium tuberculosis. FEMS Immunol Med Microbiol 21(2):149-157. https://doi.org/10.1111/j.1574695X.1998.tb01161.X

Samuels GJ, Hallett IC (1983) Microdochium stoveri and Monographella stoveri, new combinations for Fusarium stoveri and Micronectriella stoveri. Trans Brit Mycol Soc 81(3):473-483. https://doi.org/10.1016/S0007-1536(83)80115-6

Scebba F, Sebustiani L, Vitagliano C (1999) Protective enzymes against activated oxygen species in wheat (Triticum aestivum L.) seedlings: responses to cold acclimation. J Plant Physiol 155:762768. https://doi.org/10.1016/S0176-1617(99)80094-7

Shigeoka S, Ishikawa T, Tamoi M, Miyagawa Y, Takeda T, Yabuta Y, Yoshimura K (2002) Regulation and function of ascorbate peroxidase isoenzymes. J Exp Bot 53:1305-1319. https://doi. org/10.1093/jexbot/53.372.1305

Siranidou E, Kang Z, Buchenauer H (2002) Studies on symptom development, phenolic compounds and morphological defence responses in wheat cultivars differing in resistance to Fusarium head blight. J Phytopathol 150:200-208. https://doi.org/10.104 6/j.1439-0434.2002.00738.x

Sliesaravičius A, Pekarskas J, Baranauskis K (2006) Grain yield and disease resistance of winter cereal varieties and application of biological agent in organic agriculture. Agron Res 4(Special issue):371-378

Southerton SG, Deverall BJ (1990) Changes in phenolic acid levels in wheat leaves expressing resistance tolerance to Puccinia recondita f. sp. tritici. Physiol Mol Plant Pathol 37(6):437-450. https://doi. org/10.1016/0885-5765(90)90035-V

Szechyńska-Hebda M, Wędzony M, Tyrka M, Gołębiowska G, Chrupek M, Czyczyło-Mysza I, Dubas E, Żur I, Golemiec E (2011) Identifying QTL for cold-induced resistance to Microdochium nivale in winter triticale. Plant Genet Resour 9: 296-299

Szechyńska-Hebda M, Hebda M, Mierzwiński D, Kuczyńska P, Mirek M, Wędzony M, van Lammeren A, Karpiński S (2013) Effect of cold-induced changes in physical and chemical leaf properties on the resistance of winter triticale $(\times$ Triticosecale) to the fungal pathogen Microdochium nivale. Plant Pathol 62(4):867-878. https ://doi.org/10.1111/ppa.12001

Tyrka M, Tyrka D, Wedzony M (2015) Genetic Map of Triticale Integrating Microsatellite, DArT and SNP Markers. PLoS One 10(12): e0145714

Wang D, Pajerowska-Mukhtar K, Culler AH, Dong X (2007) Salicylic acid inhibits pathogen growth in plants through repression of the auxin signalling pathway. Curr Biol 17(20):1784-1790. https:// doi.org/10.1016/j.cub.2007.09.025

Wędzony M (2003) Protocol for doubled haploid production in hexaploid triticale (x Triticosecale Wittm.) by crosses with maize. A manual. In: Małuszynski M (ed) Doubled haploid production in crop plants. Kluwer Academic Publisher, Dordrecht, 123-128

Yoon BH, Jung JW, Lee JJ, Cho YW, Jang CG, Jin C, Oh TH, Ryu JH (2007) Anxiolytic-like effects of sinapic acid in mice. Life Sci 81:234-240. https://doi.org/10.1016/j.lfs.2007.05.007 
Zadoks JC, Chang TT, Konzak CF (1974) A decimal code for the growth stages of cereals. Weed Res 14:415-421

Zhukovsky A, Ilyuk A (2010) Pleśń śniegowa w uprawach pszenżyta ozimego i skuteczność zapraw nasiennych na Białorusi. Prog Plant Prot 50(4): 1841-1846

Żur I, Dubas E, Pociecha E, Dubert F, Kolasińska I, Płażek A (2011) Cytological analysis of infection process and the first defence responses induced in winter rye (Secale cereale L.) seedlings inoculated with Microdochium nivale. Physiol Mol Plant P 76:189-196. https://doi.org/10.1016/j.pmpp.2011.09.007

Żur I, Gołębiowska G, Dubas E, Golemiec E, Matušíková I, Libantová J, Moravčiková J (2013) $\beta$-1,3-glucanase and chitinase activities in winter triticales during cold hardening and subsequent infection by Microdochium nivale. Biologia 68(2):241-248. https://doi. org/10.2478/s11756-013-0001-0

Publisher's Note Springer Nature remains neutral with regard to jurisdictional claims in published maps and institutional affiliations. 